\title{
Long-term comparison of everolimus-eluting stents with sirolimus- and paclitaxel-eluting stents for percutaneous coronary intervention of saphenous vein grafts
}

\author{
Masanori Taniwaki ${ }^{1}, \mathrm{MD}$; Lorenz Räber ${ }^{1}, \mathrm{MD}$; Michael Magro², MD; Bindu Kalesan³, MSc; \\ Yoshinobu Onuma ${ }^{2}, \mathrm{MD}$; Giulio G. Stefanini ${ }^{1}$, MD; Ron T. van Domburg ${ }^{2}$, PhD; Aris Moschovitis ${ }^{1}$, MD; \\ Bernhard Meier ${ }^{1}$, MD; Peter Jüni ${ }^{3,4}$, MD; Patrick W. Serruys ${ }^{2}$, MD, PhD; Stephan Windecker ${ }^{1,4 *}$, MD \\ 1. Swiss Cardiovascular Center, Bern University Hospital, Bern, Switzerland; 2. Thoraxcenter, Erasmus Medical Center, \\ Rotterdam, The Netherlands; 3. Institute of Social and Preventive Medicine, University of Bern, Bern, Switzerland; 4. Clinical \\ Trials Unit Bern, University of Bern, Bern, Switzerland
}

GUEST EDITOR: Andreas Baumbach, MD; Bristol Heart Institute, University Hospitals Bristol, Bristol, United Kingdom

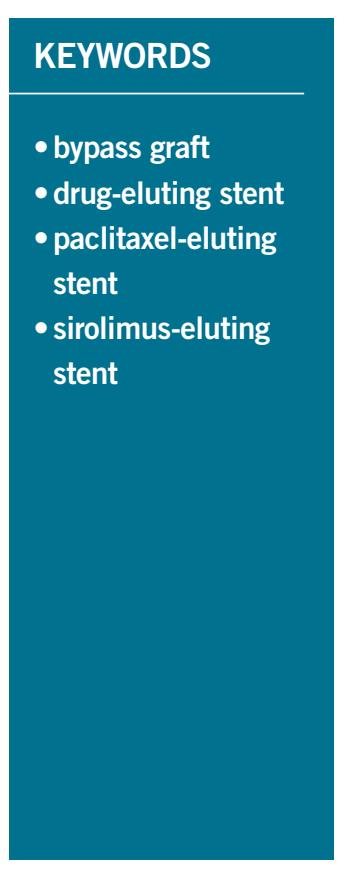

\begin{abstract}
Aims: Newer-generation everolimus-eluting stents (EES) have been shown to improve clinical outcomes compared with early-generation sirolimus-eluting (SES) and paclitaxel-eluting stents (PES) in patients undergoing percutaneous coronary intervention (PCI). Whether this benefit is maintained among patients with saphenous vein graft (SVG) disease remains controversial.
\end{abstract}

Methods and results: We assessed cumulative incidence rates (CIR) per 100 patient years after inverse probability of treatment weighting to compare clinical outcomes. The pre-specified primary endpoint was the composite of cardiac death, myocardial infarction (MI), and target vessel revascularisation (TVR). Out of 12,339 consecutively treated patients, 288 patients $(5.7 \%)$ underwent PCI of at least one SVG lesion with EES ( $n=127)$, SES $(n=103)$ or PES ( $n=58)$. Up to four years, CIR of the primary endpoint were 58.7 for EES, 45.2 for SES and 45.6 for PES with similar adjusted risks between groups (EES vs. SES; HR 0.94, 95\% CI: 0.55-1.60, EES vs. PES; HR 1.07, 95\% CI: 0.60-1.91). Adjusted risks showed no significant differences between stent types for cardiac death, MI and TVR.

Conclusions: Among patients undergoing PCI for SVG lesions, newer-generation EES have similar safety and efficacy to early-generation SES and PES during long-term follow-up to four years.

\footnotetext{
*Corresponding author: Swiss Cardiovascular Center, Bern University Hospital, Freiburgstrasse, 3010 Bern, Switzerland. E-mail: stephan.windecker@insel.ch
} 


\section{Abbreviations}

$\begin{array}{ll}\text { ARC } & \text { Academic Research Consortium } \\ \text { BMS } & \text { bare metal stent(s) } \\ \text { CIR } & \text { cumulative incidence rates } \\ \text { DES } & \text { drug-eluting stent(s) } \\ \text { EES } & \text { everolimus-eluting stent(s) } \\ \text { HR } & \text { hazard ratio } \\ \text { IQR } & \text { interquartile range } \\ \text { MACE } & \text { major adverse cardiac events } \\ \text { MI } & \text { myocardial infarction } \\ \text { NSTEMI } & \text { non-ST-segment elevation myocardial infarction } \\ \text { PCI } & \text { percutaneous coronary intervention } \\ \text { PES } & \text { paclitaxel-eluting stent(s) } \\ \text { SD } & \text { standard deviation } \\ \text { SES } & \text { sirolimus-eluting stent(s) } \\ \text { ST } & \text { stent thrombosis } \\ \text { STEMI } & \text { ST-segment elevation myocardial infarction } \\ \text { SVG } & \text { saphenous vein graft } \\ \text { TVR } & \text { target vessel revascularisation } \\ \text { ULN } & \text { upper limit of normal }\end{array}$

\section{Introduction}

Approximately 3-6\% of percutaneous coronary interventions (PCI) are performed among patients with saphenous vein graft (SVG) disease ${ }^{1}$, and this represents the most important revascularisation option for patients with graft failure. PCI of SVG lesions is characterised by high rates of restenosis and periprocedural myocardial infarction (MI) compared with revascularisation of native coronary arteries. Compared with bare metal stents (BMS), drug-eluting stents (DES) have been shown to reduce the risk of repeat revascularisation by $50 \%$, related to a potent inhibition of neointimal tissue proliferation ${ }^{2}$ without differences in terms of cardiac death or MI in the largest randomised trial performed to date ${ }^{3,4}$ However, early-generation DES releasing sirolimus (SES) or paclitaxel (PES) from durable polymers were used in two thirds of patients enrolled in this study ${ }^{1}$, and little is known regarding the outcomes of newer-generation DES among patients with SVG disease. The newer-generation everolimus-eluting stent (EES) is a thinstrut, cobalt-chromium alloy stent, which is coated with a durable, fluorinated co-polymer releasing a reduced dose of everolimus compared to the dose used with SES ${ }^{5}$. EES have been shown to improve efficacy and safety compared with early-generation $\mathrm{PES}^{6-8}$ through two years and to provide similar efficacy but improved safety compared with early-generation $\mathrm{SES}^{9,10}$ in a wide range of patients and lesions. However, it is unknown whether the favourable results with the use of newer-generation EES remain sustained among patients undergoing PCI for SVG disease. We therefore investigated the long-term clinical outcomes of patients undergoing PCI of SVG lesions with the use of EES compared with SES and PES in a large-scale registry.

\section{Methods \\ PATIENT POPULATION}

The Bern-Rotterdam registry evaluates clinical outcomes of patients treated with the unrestricted use of DES enrolled at Bern
University Hospital, Bern, Switzerland, and the Thoraxcenter, Erasmus Medical Center, Rotterdam, The Netherlands.

Primary results with focus on stent thrombosis have been reported previously ${ }^{6,7,11}$. In the Dutch institution, SES had been used as a default strategy for PCI as part of the Rapamycin-Eluting Stent Evaluated At Rotterdam Cardiology Hospital (RESEARCH) registry. From the first quarter of 2003, PES became commercially available and replaced SES as default device and became part of the TAXUS Stent Evaluated At Rotterdam Cardiology Hospital (T-SEARCH) registry. EES (XIENCE V ${ }^{\circledR}$; Abbott Vascular, Santa Clara, CA, USA, or PROMUS ${ }^{\circledR}$; Boston Scientific, Natick, MA, USA) had been used as a default strategy for PCI as part of the XIENCE Stent Evaluated At Rotterdam Cardiology Hospital (X-SEARCH) registry since March 1, 2007, until the end of this study period. In the Swiss institution, EES had been used since November 1, 2006, and were implanted on a daily basis alternating with biolimus-eluting stents and zotarolimus-eluting stents. SES had been used since April, 2002, and PES since March, 2003. Individual patients who had been treated with more than one type of DES were excluded from the current registry. The study was approved by the local ethics committee at both institutions and was in accordance with the Declaration of Helsinki. Written informed consent was obtained from all patients.

\section{DATA COLLECTION}

All patients were actively followed for major adverse cardiac events using patient administered postal questionnaires including questions on rehospitalisation and major adverse cardiac events. This was complemented by a search of hospital databases at the two institutions. In Bern, the last follow-up took place from February 1, 2007, onwards for patients who had undergone implantation of SES or PES and from February 1, 2010, onwards for patients with EES. In Rotterdam, the last follow-up took place from July 1, 2005, onwards for patients with PES, July 1, 2006, for patients with SES, and April 1, 2010, onwards for patients with EES, respectively. For patients with a suspected event, relevant medical records, discharge letters, and coronary angiography documentation were systematically collected. All suspected clinical events were adjudicated by local cardiologists affiliated with the two institutions, whereas all ST events were adjudicated by an independent clinical events committee whose members were unaware of the type of stent implanted. Baseline clinical and procedural characteristics and all follow-up data were entered into a dedicated database, held at an academic clinical trials unit (CTU Bern, Bern University Hospital, Bern, Switzerland) responsible for central data audits and maintenance of the database.

\section{PROCEDURES}

EES were available in diameters from 2.25 to $4.0 \mathrm{~mm}$ and in lengths from 8 to $28 \mathrm{~mm}$; SES were available in diameters from 2.25 to $3.5 \mathrm{~mm}$ and in lengths from 8 to $33 \mathrm{~mm}$, and PES were available in diameters from 2.25 to $4.0 \mathrm{~mm}$ and in lengths from 8 to $32 \mathrm{~mm}$. The procedure and treatment including peri- and post-procedural 
medication regimen were performed according to current practice guidelines. All patients irrespective of stent type received a loading dose of clopidogrel $300 \mathrm{mg}$ to $600 \mathrm{mg}$ during or immediately after the procedure and were prescribed aspirin once daily lifelong. In the Dutch institution, clopidogrel was administered to patients with SES for at least three months, and for at least six months if patients had received three or more stents, the total stent length was $>36 \mathrm{~mm}$, or a chronic total occlusion or bifurcation was treated. Dutch patients treated with EES were prescribed clopidogrel for 12 months. In the Swiss institution, all patients were prescribed clopidogrel for a duration of at least 12 months irrespective of stent type. The use of glycoprotein IIb/IIIa antagonists and distal protection devices was left at the discretion of the operator.

\section{DEFINITIONS}

The primary endpoint of this study was major adverse cardiac events (MACE) defined as the composite of cardiac death, MI, and target vessel revascularisation up to four years. The definition of cardiac death included any death due to immediate cardiac cause, procedurerelated deaths, unwitnessed death and death of unknown cause. The diagnosis of MI was based on an elevation in CK to more than twice the upper limit of normal (ULN) and an elevation of CK-MB to more than three times ULN in the presence of ischaemic symptoms or ischaemic ECG changes. Target vessel revascularisation (TVR) was defined as any repeat percutaneous intervention or surgical bypass of any segment within the entire major coronary vessel proximal and distal to the target lesion, including upstream and downstream branches and the target lesion itself. Target lesion revascularisation (TLR) was defined as a repeated revascularisation due to a stenosis within the stent or within the $5 \mathrm{~mm}$ borders proximal or distal to the stent. A 12-lead electrocardiogram was obtained prior to the procedure and within 24 hours after PCI. Additional ECGs were obtained in case of recurrent signs or symptoms of ischaemia. Acute coronary syndrome was defined as acute myocardial ischaemia based on clinical symptoms, electrocardiographic changes, and elevation of cardiac biomarkers, and encompassed an acute ST-segment (STEMI) and non-ST-segment elevation myocardial infarction (NSTEMI) and unstable angina. Definitions of hypertension, hyperlipidaemia and renal dysfunction were reported previously ${ }^{7,11}$. Stent thrombosis was defined according to the Academic Research Consortium (ARC) $)^{8,9}$.

\section{STATISTICAL ANALYSIS}

Baseline clinical and procedural characteristics of the three stent types are presented as counts and percentages for dichotomous variables and as mean and standard deviation (SD) for continuous variables. Pearson's chi-square test and Student's t-test were used for comparing dichotomous and continuous variables, respectively. Cumulative incidence rates (CIR) per 100 patient years were calculated for each endpoint, defined as the number of new events occurring during a specific time period divided by the total number of patient years observed. In contrast to crude percentages, CIR take into account differences in follow-up duration between different stent types. Propensity scores for receiving EES were estimated for each centre by the use of a logit model including age, gender and pre-treatment variables associated with stent selection at $\mathrm{p}<0.10$ (i.e., family history of coronary artery disease, acute coronary syndrome and cardiogenic shock for both centres; body mass index and left ventricular ejection fraction as additional variables for Bern; arterial hypertension, smoking, diabetes and hyperlipidaemia as additional variables for Rotterdam). Propensity scores were used to derive inverse probability of treatment weights, with the inverse of propensity score as analytical weights in EES-treated patients and the inverse of 1 minus the propensity score among early-generation DES-treated patients. Comparisons between stent types were performed with a Cox proportional hazards model, crude and adjusted using inverse probability of treatment weighting. All statistical analyses were performed using STATA release 11.1 (StataCorp, College Station, TX, USA). All p-values are two-sided.

\section{Results}

Between April 16, 2002, and March 31, 2009, 12,339 consecutive patients underwent treatment with the unrestricted use of EES $(n=4,212)$, SES $(n=3,819)$ and PES $(n=4,308)$. Out of this cohort, 288 patients (5.7\%) (177 [61.5\%] enrolled at Bern University Hospital, and 111 [38.5\%] included at Thoraxcenter, Rotterdam) underwent PCI of at least one SVG lesion with the use of EES among 127 patients, SES among 103 patients, and PES among 58 patients. Baseline clinical characteristics for all three stent types are summarised in Table 1. Patients treated with EES compared with those treated with either SES or PES more frequently had diabetes. Patients treated with EES were more frequently hypertensive compared to those treated with PES, and more frequently had dyslipidaemia, renal failure and presented with an acute coronary syndrome than SES-treated patients. Table 2 shows procedural characteristics, which were balanced among the three treatment groups with the exception of a larger stent diameter in lesions treated with EES compared with those treated with SES. The use of glycoprotein IIb/IIIa antagonists, aspirin, and proton pump inhibitors was more frequent among EES compared with PES-treated patients.

\section{Clinical outcome}

The median follow-up duration among surviving patients completing the last follow-up was 2.5 years in patients treated with EES (interquartile range: IQR 1.9 to 3.2 years), four years in patients treated with SES (IQR 3.0 to 4.0 years), and 3.5 years in patients treated with PES (IQR 2.3 to 4.0 years) with an accumulated 144, 266, and 302 patient years, respectively.

Clinical outcomes up to four years are summarised in Table 3 and Table 4.

Up to four years, incidence rates per 100 patient years for the primary endpoint MACE were similar among patients treated with EES (58.7\%), SES (45.2\%, adjusted HR 0.94, 95\% CI: 0.55-1.60) and PES (45.6\%, adjusted HR 1.07, 95\% CI: 0.60.-1.91) in adjusted analyses (Table 3 and Table 4, Figure 1). Similarly, there was no difference in the risk of cardiac death (EES vs. SES adjusted HR 1.18, 95\% CI: 0.49-2.84, EES vs. PES adjusted HR 0.81, 95\% CI: 0.30-2.17), 
Table 1. Baseline clinical characteristics.

\begin{tabular}{|c|c|c|c|c|c|}
\hline & \multicolumn{3}{|c|}{ Stent type } & \multicolumn{2}{|c|}{$p$-value } \\
\hline & EES (A) & SES (B) & PES (C) & A vs. $B$ & A vs. C \\
\hline Number of patients & 127 & 103 & 58 & & \\
\hline Age (yr) & $69.2(9.6)$ & $67.5(10.5)$ & $68.3(8.8)$ & 0.19 & 0.54 \\
\hline Male gender & $104(81.9)$ & $86(83.5)$ & $53(91.4)$ & 0.75 & 0.09 \\
\hline Body mass index $\left(\mathrm{kg} / \mathrm{m}^{2}\right)$ & $27.7(3.6)$ & $27.2(3.7)$ & $27.4(3.8)$ & 0.27 & 0.64 \\
\hline Hypertension & $89(70.1)$ & $67(65.0)$ & $28(48.3)$ & 0.42 & 0.004 \\
\hline Family history of CAD & $44(34.6)$ & $33(32.0)$ & $18(31)$ & 0.68 & 0.63 \\
\hline Smoking at baseline & $43(33.9)$ & $47(45.6)$ & $24(41.4)$ & 0.07 & 0.32 \\
\hline Dyslipidaemia & $101(79.5)$ & $69(67.0)$ & $39(67.2)$ & 0.031 & 0.07 \\
\hline Diabetes mellitus & $46(36.2)$ & $18(17.5)$ & $11(19)$ & 0.002 & 0.018 \\
\hline Renal failure (GFR $<60 \mathrm{ml} / \mathrm{min}$ )* & $12(21.4)$ & $11(13.4)$ & $8(20.5)$ & 0.21 & 0.91 \\
\hline Renal failure (creatinine $>150 \mu \mathrm{mol} / \mathrm{l}$ )* & $4(7.1)$ & $0(0)$ & $2(5.1)$ & 0.014 & 0.69 \\
\hline Left ventricular ejection fraction, $<30 \%$ & $3(6.3)$ & $6(7.8)$ & $3(8.8)$ & 0.75 & 0.66 \\
\hline Acute coronary syndrome & $74(58.3)$ & 39 (37.9) & $26(44.8)$ & 0.002 & 0.09 \\
\hline Unstable angina/non-ST-elevation MI & $57(77.0)$ & $34(87.2)$ & $23(88.5)$ & 0.20 & 0.21 \\
\hline ST-elevation MI & $17(23.0)$ & $5(12.8)$ & $3(11.5)$ & - & - \\
\hline Cardiogenic shock & $1(0.8)$ & $0(0)$ & $0(0)$ & 0.37 & 0.50 \\
\hline
\end{tabular}

A

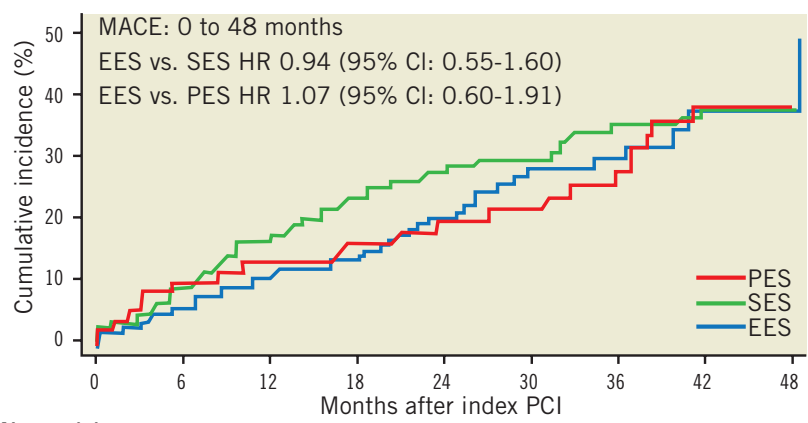

No. at risk

$\begin{array}{rrrrrrrrrr}\text { PES } & 57 & 50 & 47 & 39 & 37 & 33 & 29 & 19 & 11 \\ \text { SES } & 103 & 91 & 82 & 73 & 64 & 59 & 46 & 36 & 33 \\ \text { EES } & 126 & 112 & 103 & 91 & 64 & 43 & 29 & 14 & 4\end{array}$

B 50 Cardiac death: 0 to 48 months

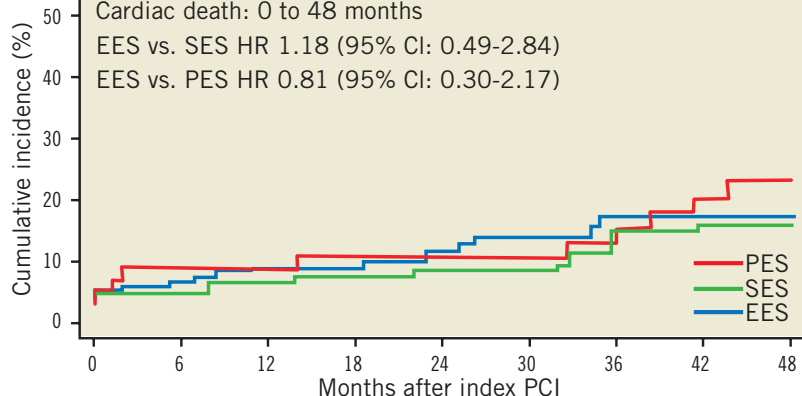

No. at risk

$\begin{array}{lrrrrrrrrr}\text { PES } & 58 & 55 & 54 & 46 & 46 & 39 & 35 & 26 & 15 \\ \text { SES } & 103 & 102 & 100 & 96 & 91 & 84 & 67 & 56 & 50 \\ \text { EES } & 127 & 118 & 113 & 104 & 79 & 60 & 38 & 21 & 10\end{array}$

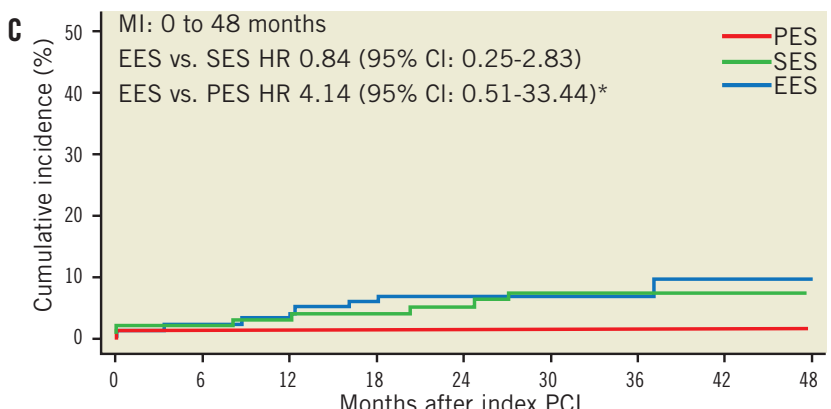

No. at risk

$\begin{array}{lrrrrrrrrr}\text { PES } & 58 & 54 & 53 & 45 & 45 & 39 & 35 & 26 & 15 \\ \text { SES } & 103 & 100 & 98 & 94 & 88 & 79 & 63 & 53 & 47 \\ \text { EES } & 127 & 116 & 109 & 98 & 73 & 55 & 35 & 19 & 8\end{array}$

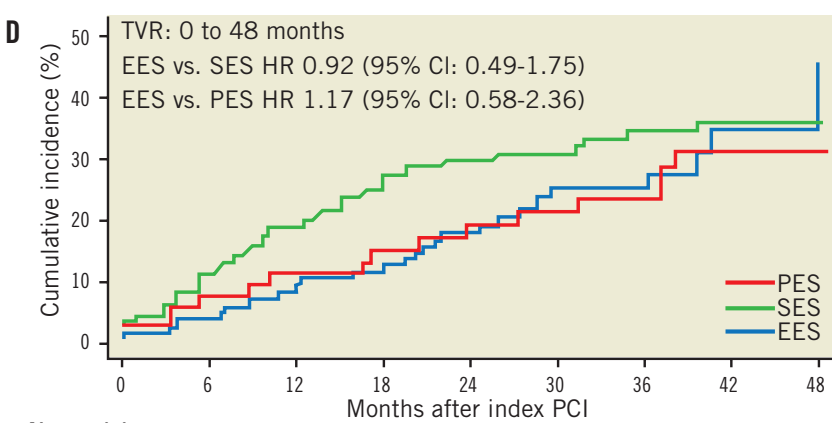

No. at risk

$\begin{array}{lrrrrrrrrr}\text { PES } & 58 & 52 & 49 & 41 & 39 & 34 & 30 & 20 & 12 \\ \text { SES } & 103 & 93 & 84 & 74 & 65 & 60 & 47 & 36 & 33 \\ \text { EES } & 127 & 114 & 105 & 93 & 66 & 45 & 31 & 16 & 6\end{array}$

Figure 1. Cumulative event curves for the primary endpoint of major adverse cardiac events (MACE) (A), cardiac death (B), myocardial infarction (MI) (C), and target vessel revascularisation (TVR) (D) up to 48 months. *Crude hazard ratio is shown, as adjusted model did not converge. EES: everolimus-eluting stents; PES: paclitaxel-eluting stents; SES: sirolimus-eluting stents 
Table 2. Baseline procedural characteristics.

\begin{tabular}{|c|c|c|c|c|c|}
\hline & \multicolumn{3}{|c|}{ Stent type } & \multicolumn{2}{|c|}{$p$-value } \\
\hline & EES (A) & SES (B) & PES (C) & A vs. $B$ & A vs. $C$ \\
\hline Total (n) & 127 & 103 & 58 & & \\
\hline Multivessel treatment & $20(15.7)$ & $22(21.4)$ & $11(19.0)$ & 0.27 & 0.59 \\
\hline Number of vessels treated per patient & $1.2(0.4)$ & $1.2(0.6)$ & $1.2(0.4)$ & 0.29 & 0.80 \\
\hline Number of lesions treated per patient & $1.4(0.6)$ & $1.4(0.8)$ & $1.3(0.5)$ & 0.68 & 0.34 \\
\hline 1 lesion & $40(71.4)$ & $55(67.1)$ & $30(76.9)$ & - & - \\
\hline 2 lesions & $11(19.6)$ & $19(23.2)$ & $8(20.5)$ & - & - \\
\hline 3 lesions & $5(8.9)$ & $4(4.9)$ & $1(2.6)$ & - & - \\
\hline Number of stents per patient & $1.9(1.1)$ & $2.1(1.2)$ & $1.8(1.0)$ & 0.33 & 0.41 \\
\hline Average stent diameter & $3.2(0.5)$ & $3(0.3)$ & $3.2(0.5)$ & 0.0002 & 0.35 \\
\hline Total stent length per patient & $32.4(23.0)$ & $37.6(24.4)$ & $33.1(26.5)$ & 0.10 & 0.86 \\
\hline Glycoprotein IIb/IIla antagonist & $26(20.5)$ & $14(13.6)$ & $2(3.4)$ & 0.17 & 0.003 \\
\hline \multicolumn{6}{|l|}{ Medication at discharge } \\
\hline Aspirin & $123(100)$ & 99 (98.0) & $56(96.6)$ & 0.12 & 0.038 \\
\hline Clopidogrel & $123(100)$ & $99(99.0)$ & $57(98.3)$ & 0.27 & 0.14 \\
\hline Oral anticoagulation & $7(5.7)$ & $6(5.9)$ & $7(12.1)$ & 0.94 & 0.13 \\
\hline Beta-blocker & $37(66.1)$ & $54(67.5)$ & $25(64.1)$ & 0.86 & 0.84 \\
\hline ACE inhibitor & $23(41.1)$ & $39(48.8)$ & $18(46.2)$ & 0.38 & 0.62 \\
\hline AT II inhibitor & 10 (17.9) & $17(21.3)$ & $4(10.3)$ & 0.63 & 0.30 \\
\hline Calcium antagonist & $12(21.4)$ & $18(22.5)$ & $11(28.2)$ & 0.88 & 0.45 \\
\hline Statin & $52(92.9)$ & $69(86.3)$ & $33(84.6)$ & 0.23 & 0.20 \\
\hline Oral antidiabetic & $8(14.3)$ & $12(15.0)$ & $2(5.1)$ & 0.91 & 0.15 \\
\hline Insulin & $5(8.9)$ & $3(3.8)$ & $5(12.8)$ & 0.21 & 0.54 \\
\hline Diuretics & $18(32.1)$ & $20(25.0)$ & $13(33.3)$ & 0.36 & 0.90 \\
\hline Proton pump inhibitor & $21(37.5)$ & $20(25.0)$ & $6(15.4)$ & 0.12 & 0.019 \\
\hline
\end{tabular}

MI (EES vs. SES adjusted HR 0.84, 95\% CI: 0.25-2.83, EES vs. PES crude HR 4.14, 95\% CI: 0.51-33.44), and TVR (EES vs. SES adjusted HR 0.92 , 95\% CI: 0.49-1.75, EES vs. PES adjusted HR 1.17, 95\%
CI: 0.58-2.36) in adjusted analyses. The incidence rates per 100 patient years for definite ST and definite or probable ST showed no differences among stent types at any time point (Table 5).

Table 3. Clinical outcome at 1 year.

\begin{tabular}{|c|c|c|c|c|c|c|c|}
\hline & \multicolumn{3}{|c|}{ Stent type } & \multicolumn{4}{|c|}{ Adjusted analysis } \\
\hline & \multirow{2}{*}{ EES (A) } & \multirow{2}{*}{ SES (B) } & \multirow{2}{*}{ PES (C) } & \multicolumn{2}{|l|}{ A vs. $B$} & \multicolumn{2}{|l|}{ A vs. $C$} \\
\hline & & & & HR $(95 \% \mathrm{Cl})$ & $p$-value & HR $(95 \% \mathrm{Cl})$ & $p$-value \\
\hline Number of patients & 127 & 103 & 58 & & & & \\
\hline All-cause death & $13(10.4)$ & $3(2.9)$ & $4(7.0)$ & $3.71(1.06-13.03)^{*}$ & $0.04^{*}$ & $1.50(0.49-4.60)^{*}$ & $0.48^{*}$ \\
\hline Cardiac death & $7(5.8)$ & $3(2.9)$ & $3(5.3)$ & $1.18(0.20-7.05)$ & 0.85 & $0.89(0.21-3.81)$ & 0.87 \\
\hline MI & $4(3.4)$ & $3(2.9)$ & $1(1.8)$ & $0.70(0.13-3.73)$ & 0.68 & $0.47(0.03-7.40)$ & 0.59 \\
\hline TLR & $7(6.1)$ & $11(10.8)$ & $3(5.6)$ & $0.43(0.12-1.50)$ & 0.18 & $0.73(0.17-3.16)$ & 0.68 \\
\hline TVR & $10(8.6)$ & $17(16.7)$ & $5(9.3)$ & $0.34(0.10-1.13)$ & 0.08 & $0.55(0.17-1.80)$ & 0.32 \\
\hline Cardiac death/MI & $11(9.0)$ & $5(4.9)$ & $4(7.0)$ & $1.46(0.43-5.01)$ & 0.55 & $0.93(0.26-3.33)$ & 0.91 \\
\hline Cardiac death/MI/TLR & $15(12.3)$ & $15(14.6)$ & $7(12.3)$ & $0.71(0.30-1.70)$ & 0.45 & $0.75(0.28-1.99)$ & 0.56 \\
\hline Cardiac death/MI/TVR & 17 (13.9) & $21(20.4)$ & $9(15.8)$ & $0.53(0.23-1.23)$ & 0.14 & $0.63(0.26-1.50)$ & 0.29 \\
\hline \multicolumn{8}{|c|}{$\begin{array}{l}\text { Clinical outcome numbers are expressed as counts and incidence rates per } 100 \text { patient years. Adjusted risk ratios were calculated using inverse } \\
\text { probability of treatment weights as analytical weighting in Cox proportional hazard models. *Crude rates are shown, as adjusted model did not converge. } \\
\text { Cl: confidence interval; EES: everolimus-eluting stent; HR: hazard ratio; MI: myocardial infarction; PES: paclitaxel-eluting stent; SES: sirolimus-eluting } \\
\text { stent; TLR: target lesion revascularisation; TVR: target vessel revascularisation }\end{array}$} \\
\hline
\end{tabular}


Table 4. Clinical outcome up to 4 years.

\begin{tabular}{|c|c|c|c|c|c|c|c|}
\hline & \multicolumn{3}{|c|}{ Stent type } & \multicolumn{4}{|c|}{ Adjusted analysis } \\
\hline & \multirow{2}{*}{ EES (A) } & \multirow{2}{*}{ SES (B) } & \multirow{2}{*}{ PES (C) } & \multicolumn{2}{|l|}{ A vs. $B$} & \multicolumn{2}{|l|}{ A vs. C } \\
\hline & & & & HR $(95 \% \mathrm{CI})$ & $p$-value & HR $(95 \% \mathrm{Cl})$ & $p$-value \\
\hline Number of patients & 127 & 103 & 58 & & & & \\
\hline All-cause death & $22(21.5)$ & $19(19.5)$ & $11(24.8)$ & $1.01(0.52-1.97)$ & 0.98 & $0.94(0.41-2.14)$ & 0.88 \\
\hline Cardiac death & $14(15.3)$ & $12(13.2)$ & 9 (21.8) & $1.18(0.49-2.84)$ & 0.71 & $0.81(0.30-2.17)$ & 0.67 \\
\hline $\mathrm{MI}$ & $8(9.1)$ & $8(8.5)$ & $1(1.8)$ & $0.84(0.25-2.83)$ & 0.77 & $4.14(0.51-33.44)^{*}$ & $0.18^{*}$ \\
\hline TLR & $19(25.8)$ & $26(27.6)$ & $6(12.6)$ & $0.73(0.35-1.53)$ & 0.40 & $1.58(0.57-4.35)$ & 0.38 \\
\hline TVR & $28(52.0)$ & $34(35.5)$ & $14(31.0)$ & $0.92(0.49-1.75)$ & 0.81 & $1.17(0.58-2.36)$ & 0.67 \\
\hline Cardiac death/MI & $21(21.8)$ & $19(20.3)$ & $10(23.2)$ & $1.01(0.48-2.10)$ & 0.99 & $0.95(0.38-2.41)$ & 0.92 \\
\hline Cardiac death/MI/TLR & 34 (37.9) & $36(37.6)$ & $15(32.0)$ & $0.87(0.49-1.56)$ & 0.65 & $1.16(0.59-2.31)$ & 0.66 \\
\hline Cardiac death/MI/TVR ${ }^{\pi}$ & $40(58.7)$ & $44(45.2)$ & $22(45.6)$ & $0.94(0.55-1.60)$ & 0.82 & $1.07(0.60-1.91)$ & 0.81 \\
\hline
\end{tabular}

The duration of dual antiplatelet therapy differed between the two institutions. In order to analyse potential site-specific differences in outcomes comparing EES with early-generation DES, we performed a sensitivity analysis for the primary outcome and found hazards to be similar for both institutions regarding the primary endpoint (Bern EES vs. early-generation DES: HR 0.94, 95\% CI: 0.55-1.60, $\mathrm{p}=0.82$; Rotterdam EES vs. early-generation DES: HR $1.07,95 \%$ CI: $0.60-1.01, \mathrm{p}=0.82$ ).

\section{Discussion}

This is the first report comparing newer-generation EES with earlygeneration SES and PES during long-term follow-up among patients undergoing PCI for SVG disease. The main findings of our study are: 1) the use of EES resulted in similar safety and efficacy compared to the use of early-generation SES and PES among patients with SVG lesions; 2) event rates for restenosis and recurrent ischaemia were exceedingly high during follow-up through four years regardless of the type of DES implanted.

Limited data are available on the treatment of SVG lesions with coronary artery stents.

A comparison of DES with BMS in SVG lesions in a total of 5,543 patients followed for at least one year yielded similar results to those observed in other patient populations, namely a substantial improvement in the need for repeat revascularisation of the target vessel without differences in terms of MI or stent thrombosis. Differences in cardiac death were not recorded when taking into account only randomised trials ${ }^{12}$. However, conflicting results were observed among the few studies investigating outcomes beyond one year. The randomised Extended Duration of the Reduction of Restenosis In Saphenous vein grafts with Cypher stent (DELAYED RRISC) study suggested an increased risk of cardiac death and numerically lower rates of MI with SES compared with BMS as well as a loss of the initially observed lower risk of TVR during long-term follow-up. Conversely, the long-term results of the Stenting of Saphenous Vein Grafts (SOS) trial suggested a similar risk of cardiac death but a lower risk of MI as well as sustained efficacy in terms of repeat revascularisation among PES compared with BMS-treated patients with SVG disease during long-term follow-up.

Newer-generation DES have been designed to improve upon the limitations of early-generation DES by reducing stent strut thickness, increasing the biocompatibility of polymers and modifying drug content. Several randomised clinical trials as well as large-scale registries confirmed improved safety and efficacy of

Table 5. Definite or definite/probable stent thrombosis up to 4 years.

\begin{tabular}{|c|c|c|c|c|c|c|c|}
\hline & \multicolumn{3}{|c|}{ Stent type } & \multicolumn{4}{|c|}{ Adjusted analysis } \\
\hline & \multirow{2}{*}{ EES (A) } & \multirow{2}{*}{ SES (B) } & \multirow{2}{*}{ PES (C) } & \multicolumn{2}{|l|}{$A$ vs. $B$} & \multicolumn{2}{|l|}{ A vs. $C$} \\
\hline & & & & HR $(95 \% \mathrm{Cl})$ & $p$-value & HR $(95 \% \mathrm{CI})$ & $p$-value \\
\hline Number of patients & 127 & 103 & 58 & & & & \\
\hline Definite stent thrombosis & $4(4.0)$ & $3(3.1)$ & $1(2.2)$ & $1.28(0.29-5.74)^{*}$ & $0.74^{*}$ & $0.88(0.10-8.03)$ & 0.91 \\
\hline Definite or probable stent thrombosis & $9(10.1)$ & $9(9.5)$ & $3(5.7)$ & $0.79(0.24-2.61)$ & 0.69 & $0.90(0.22-3.64)$ & 0.89 \\
\hline
\end{tabular}

Clinical outcome numbers are expressed as counts and incidence rates per 100 patient years. Adjusted risk ratios were calculated using inverse probability of treatment weights as analytical weighting in Cox proportional hazard models stratified by centre. *Crude rates are shown, as adjusted model did not converge. $\mathrm{Cl}$ : confidence interval; HR: hazard ratio; EES: everolimus-eluting stent; PES: paclitaxel-eluting stent; SES: sirolimus-eluting stent 
newer-generation EES compared with PES and SES in a wide range of patient and lesion subsets. To date, only one study has compared early-generation DES with a newer-generation stent releasing sirolimus from a biodegradable polymer among patients undergoing treatment of SVG lesions and observed no difference in terms of the primary endpoint including cardiac death, MI, and repeat revascularisation ${ }^{13}$. As it relates to long-term results, no data are available at this point in time.

Our study is the first to compare newer-generation EES with early-generation SES and PES among patients undergoing PCI of SVG lesions during long-term follow-up through four years, and is of particular interest due to the unselected, consecutive patient population undergoing PCI with the unrestricted use of DES. Similar to outcomes in ISAR-CABG, outcomes for the primary endpoint and its individual components were similar for newer-generation DES compared with early-generation SES and PES. Even when considering device-specific endpoints such as cardiac death, MI and TLR as well as stent thrombosis, no differences were noted among these devices throughout the entire follow-up period.

Irrespective of stent type, adverse events were much more frequent among patients undergoing PCI of SVG lesions compared to those undergoing PCI of native coronary arteries. Specifically, rates of MACE at four years in the present study (46\%) were similar to those reported among PES-treated patients in the randomised Stenting of Saphenous Vein Grafts (SOS) trial at 35 months of follow-up $(54 \%)^{14}$. Similarly, in the Extended Duration of the Reduction of Restenosis In Saphenous vein grafts with Cypher stent (DELAYED RRISC) study ${ }^{15}$, rates of MACE amounted to $58 \%$ among SES-treated patients at a median follow-up of 32 months. These figures contrast with rates of MACE in the range of $20 \%$ among unselected patients enrolled in all-comers studies with the predominant treatment of native coronary artery lesions ${ }^{16-18}$. Of note, clinical outcomes were driven by high rates of death, restenosis of the target lesion as well as disease progression within the target vessel, reflecting the advanced stage of coronary artery disease in this patient population.

Potential explanations for the lack of benefit with newer-generation EES compared with early-generation DES in the specific subset of SVG lesions may have been the small patient population. However, considering the high event rates and the long-term follow-up, hazards would be expected to favour EES, assuming similar benefits in terms of relative risk reduction observed in pivotal trials and all-comer patient populations. Differences between SVG lesions and native coronary arteries in terms of periprocedural treatment characteristics, atherosclerotic disease burden as well as the interaction with revascularisation by means of drug-eluting stents may be of relevance. Brilakis and colleagues reported an increased risk for in-hospital mortality among patients undergoing PCI for treatment of SVG compared to native coronary artery lesions (HR $1.22,95 \%$ CI: $1.12-1.32, \mathrm{p}<0.001)$. This was related to differences in patient and lesion risk profile and a higher incidence of acute complications such as no reflow ${ }^{19}$. SVG failure remote from the stented lesion (TVR without TLR) occurs in $30-50 \%$ of all repeat revascularisation procedures. This proportion is certainly higher compared with lesions involving native coronary arteries ${ }^{20,21}$, suggesting that non-stented disease progression remains an important adverse event among patients with SVG disease. Although rates of target lesion revascularisation during the first year in the present study were very much comparable to those observed following treatment of native coronary artery lesions, recurrent ischaemia related to the stented segment became increasingly apparent at a later time, suggesting a considerable lack of long-term efficacy. Specifically, annual rates of TLR between the first and fourth year of follow-up were 50 to $70 \%$ higher compared with annual rates previously reported in the context of native coronary artery disease $^{16}$. Therefore, SVG lesions continue to represent an important lesion subset with inadequate efficacy following the use of newergeneration DES.

Pathological analyses and experimental animal models have contributed to our understanding of accelerated atherosclerosis in SVG lesions ${ }^{22}$. Mechanical stress induced by a substantial change in haemodynamics from a venous to an arterial circulation has been identified as an important source of saphenous vein graft wall thickening, largely related to gene expression of adhesion molecules, which evoke inflammatory processes and signal pathways resulting in proliferative cell growth. Neointimal formation is followed by macrophage infiltration and eventually necrotic core formation, resulting in vulnerable plaque formation. Stent implantation of SVG lesions more often lead to strut penetration into the necrotic core, which may delay healing and perpetuate inflammation, compared with stents implanted into native coronary artery lesions resulting in an increased risk for thrombotic occlusions ${ }^{23}$. In addition, neoatherosclerotic changes have been observed as early as one year after stent implantation in SVG lesions, which is more premature than observed in native coronary artery lesions. Although the prevalence of neoatherosclerosis within DES-treated SVG lesions has not been assessed to date, pathology studies suggest that neoatherosclerosis is an important mechanism contributing to restenosis during long-term follow-up, providing a potential explanation for the high TLR rates observed in this study beyond one year.

Very late stent thrombosis is one of the major concerns with the use of early-generation DES; however, the use of EES was associated with a substantial reduction in an all-comers patient population ${ }^{9,10}$. In the present study, there were no differences among the three stent platforms. However, event rates and patient population were small, precluding further exploration of differences among devices.

\section{Limitations}

The present study has to be interpreted in view of the following limitations. First, this study was not specially designed to compare the safety and efficacy of newer-generation EES with early-generation DES in SVG lesions. The data are derived from a non-randomised, observational cohort. Second, we lack information regarding the diameter of SVG lesions, the use of distal protection devices, and the age of SVGs at the time point of the intervention. Third, patients were enrolled during different time periods and advances in interventional 
techniques (e.g., more frequent post-dilatation) may have impacted on results. In addition, the follow-up period differed among the three treatment groups. However, we employed statistical methodologies to present adjusted analyses by employing inverse probability of treatment weights and the reporting of cumulative incidence rates. Finally, the sample size of this study is small; larger patient populations are needed to address more definitively the value of newergeneration DES in SVG lesions.

\section{Conclusions}

Among patients undergoing PCI for SVG lesions, newer-generation EES provide similar safety and efficacy compared to earlygeneration SES and PES during long-term follow-up. The high rates of adverse events among patients with SVG disease are related to disease progression of treated and untreated SVG segments.

\section{Guest Editor}

This paper was Guest Edited by Andreas Baumbach, MD; Bristol Heart Institute, University Hospitals Bristol, Bristol, United Kingdom

\section{Conflict of interest statement}

M. Taniwaki is the recipient of a research grant from Abbott and OrbusNeich. S. Windecker has received research grants from Abbott, Boston Scientific, Biosensors, Cordis, Medtronic and St. Jude. B. Meier has received research grants from Abbott and Cordis. The other authors have no conflicts of interest to declare. The Guest Editor has no conflicts of interest to declare.

\section{References}

1. Brilakis ES, Wang TY, Rao SV, Banerjee S, Goldman S, Shunk K, Kar B, Holmes DR Jr, Dai D, Chin CT, Harding TM, Roe MT. Frequency and predictors of drug-eluting stent use in saphenous vein bypass graft percutaneous coronary interventions: a report from the American College of Cardiology National Cardiovascular Data CathPCI registry. JACC Cardiovasc Interv. 2010;3:1068-73.

2. Jeroudi OM, Abdel-Karim AR, Michael TT, Lichtenwalter C, de Lemos JA, Obel O, Addo T, Roesle M, Haagen D, Rangan BV, Raghunathan D, DaSilva M, Saeed B, Bissett JK, Sachdeva R, Voudris VV, Karyofillis P, Kar B, Rossen J, Fasseas P, Berger P, Banerjee S, Brilakis ES. Paclitaxel-eluting stents reduce neointimal hyperplasia compared to bare metal stents in saphenous vein grafts: intravascular ultrasonography analysis of the SOS (Stenting of Saphenous Vein Grafts) trial. EuroIntervention. 2011;7:948-54.

3. Moses JW, Leon MB, Popma JJ, Fitzgerald PJ, Holmes DR, O'Shaughnessy C, Caputo RP, Kereiakes DJ, Williams DO, Teirstein PS, Jaeger JL, Kuntz RE. Sirolimus-eluting stents versus standard stents in patients with stenosis in a native coronary artery. N Engl J Med. 2003;349:1315-23.

4. Stone GW, Ellis SG, Cox DA, Hermiller J, O'Shaughnessy C, Mann JT, Turco M, Caputo R, Bergin P, Greenberg J, Popma JJ, Russell ME. A polymer-based, paclitaxel-eluting stent in patients with coronary artery disease. $N$ Engl J Med. 2004;350:221-31.
5. Sheiban I, Villata G, Bollati M, Sillano D, Lotrionte M, Biondi-Zoccai G. Next-generation drug-eluting stents in coronary artery disease: focus on everolimus-eluting stent (Xience V). Vasc Health Risk Manag. 2008;4:31-8.

6. Stone GW, Rizvi A, Newman W, Mastali K, Wang JC, Caputo R, Doostzadeh J, Cao S, Simonton CA, Sudhir K, Lansky AJ, Cutlip DE, Kereiakes DJ. Everolimus-eluting versus paclitaxel-eluting stents in coronary artery disease. N Engl J Med. 2010;362:1663-74.

7. Stone GW, Midei M, Newman W, Sanz M, Hermiller JB, Williams J, Farhat N, Mahaffey KW, Cutlip DE, Fitzgerald PJ, Sood P, Su X, Lansky AJ. Comparison of an everolimus-eluting stent and a paclitaxel-eluting stent in patients with coronary artery disease: a randomized trial. JAMA. 2008;299:1903-13.

8. Kedhi E, Joesoef KS, McFadden E, Wassing J, van Mieghem C, Goedhart D, Smits PC. Second-generation everolimus-eluting and paclitaxel-eluting stents in real-life practice (COMPARE): a randomised trial. Lancet. 2010;375:201-9.

9. Räber L, Magro M, Stefanini GG, Kalesan B, van Domburg RT, Onuma Y, Wenaweser P, Daemen J, Meier B, Jüni P, Serruys PW, Windecker S. Very late coronary stent thrombosis of a newer-generation everolimus-eluting stent compared with early-generation drug-eluting stents: a prospective cohort study. Circulation. 2012;125:1110-21.

10. Palmerini T, Biondi-Zoccai G, Riva DD, Stettler C, Sangiorgi D, D'Ascenzo F, Kimura T, Briguori C, Sabate M, Kim HS, De Waha A, Kedhi E, Smits PC, Kaiser C, Sardella G, Marullo A, Kirtane AJ, Leon MB, Stone GW. Stent thrombosis with drug-eluting and bare-metal stents: evidence from a comprehensive network meta-analysis. Lancet. 2012;379:1393-402.

11. Daemen J, Wenaweser P, Tsuchida K, Abrecht L, Vaina S, Morger C, Kukreja N, Jüni P, Sianos G, Hellige G, van Domburg RT, Hess OM, Boersma E, Meier B, Windecker S, Serruys PW. Early and late coronary stent thrombosis of sirolimus-eluting and paclitaxel-eluting stents in routine clinical practice: data from a large two-institutional cohort study. Lancet. 2007;369:667-78.

12. Sanchez-Recalde A, Jimenez Valero S, Moreno R, Barreales L, Lozano I, Galeote G, Martin Reyes R, Calvo L, Lopez-Sendon JL. Safety and efficacy of drug-eluting stents versus bare-metal stents in saphenous vein grafts lesions: a meta-analysis. EuroIntervention. 2010;6:149-60.

13. Mehilli J, Pache J, Abdel-Wahab M, Schulz S, Byrne RA, Tiroch K, Hausleiter J, Seyfarth M, Ott I, Ibrahim T, Fusaro M, Laugwitz KL, Massberg S, Neumann FJ, Richardt G, Schomig A, Kastrati A. Drug-eluting versus bare-metal stents in saphenous vein graft lesions (ISAR-CABG): a randomised controlled superiority trial. Lancet. 2011;378:1071-8.

14. Brilakis ES, Lichtenwalter C, Abdel-karim AR, de Lemos JA, Obel O, Addo T, Roesle M, Haagen D, Rangan BV, Saeed B, Bissett JK, Sachdeva R, Voudris VV, Karyofillis P, Kar B, Rossen J, Fasseas P, Berger P, Banerjee S. Continued benefit from paclitaxeleluting compared with bare-metal stent implantation in saphenous vein graft lesions during long-term follow-up of the SOS (Stenting of Saphenous Vein Grafts) trial. JACC Cardiovasc Interv. 2011;4:176-82. 
15. Vermeersch $P$, Agostoni $P$, Verheye S, Van den Heuvel $P$, Convens C, Van den Branden F, Van Langenhove G. Increased late mortality after sirolimus-eluting stents versus bare-metal stents in diseased saphenous vein grafts: results from the randomized DELAYED RRISC Trial. J Am Coll Cardiol. 2007;50:261-7.

16. Raber L, Wohlwend L, Wigger M, Togni M, Wandel S, Wenaweser P, Cook S, Moschovitis A, Vogel R, Kalesan B, Seiler C, Eberli F, Luscher TF, Meier B, Jüni P, Windecker S. Fiveyear clinical and angiographic outcomes of a randomized comparison of sirolimus-eluting and paclitaxel-eluting stents: results of the Sirolimus-Eluting Versus Paclitaxel-Eluting Stents for Coronary Revascularization LATE trial. Circulation. 2011;123:2819-28, 6 p following 2828.

17. Stefanini GG, Kalesan B, Serruys PW, Heg D, Buszman P, Linke A, Ischinger T, Klauss V, Eberli F, Wijns W, Morice MC, Di Mario C, Corti R, Antoni D, Sohn HY, Eerdmans P, van Es GA, Meier B, Windecker S, Jüni P. Long-term clinical outcomes of biodegradable polymer biolimus-eluting stents versus durable polymer sirolimuseluting stents in patients with coronary artery disease (LEADERS): 4 year follow-up of a randomised non-inferiority trial. Lancet. 2011;378:1940-8.

18. Silber S, Windecker S, Vranckx P, Serruys PW. Unrestricted randomised use of two new generation drug-eluting coronary stents: 2-year patient-related versus stent-related outcomes from the RESOLUTE All Comers trial. Lancet. 2011;377:1241-7.

19. Brilakis ES, Rao SV, Banerjee S, Goldman S, Shunk KA, Holmes DR Jr, Honeycutt E, Roe MT. Percutaneous coronary intervention in native arteries versus bypass grafts in prior coronary artery bypass grafting patients: a report from the National Cardiovascular Data Registry. JACC Cardiovasc Interv. 2011;4:844-50.

20. Ellis SG, Brener SJ, DeLuca S, Tuzcu EM, Raymond RE, Whitlow PL, Topol EJ. Late myocardial ischemic events after saphenous vein graft intervention--importance of initially "nonsignificant" vein graft lesions. Am J Cardiol. 1997;79:1460-4.

21. Keeley EC, Velez CA, O'Neill WW, Safian RD. Long-term clinical outcome and predictors of major adverse cardiac events after percutaneous interventions on saphenous vein grafts. $J \mathrm{Am}$ Coll Cardiol. 2001;38:659-65.

22. Zou Y, Dietrich H, Hu Y, Metzler B, Wick G, Xu Q. Mouse model of venous bypass graft arteriosclerosis. Am J Pathol. 1998;153:1301-10.

23. Yazdani SK, Farb A, Nakano M, Vorpahl M, Ladich E, Finn AV, Kolodgie FD, Virmani R. Pathology of drug-eluting versus bare-metal stents in saphenous vein bypass graft lesions. JACC Cardiovasc Interv. 2012;5:666-74. 